International Journal of Geography and Geology

2014. Vol. 3, No. 1, pp. 1-8

$\operatorname{ISSN}(e): 2305-7041$

$\operatorname{ISSN}(p): 2306-9872$

DOI: $10.18488 /$ journal.10/2014.3.1/10.1.1.8

(C) 2014 Conscientia Beam. All Rights Reserved.

(CrossMark

\title{
COMPARISON AND REVIEW OF THE ADVANTAGES OF THE FRACTAL METHOD (VARIOGRAM) WITH RESPECT TO THE NETTELTON IN DETERMINING THE DENSITY OF THE BOUGUER PLANE IN THE SOUTHERN HORMOZGAN: IRAN
}

\author{
Samadi Hamid Reza' ${ }^{1}$--- Teymoorian Asghar ${ }^{2}$ \\ ${ }^{\prime}$ Member of Young Researchers Club, Ardestan Branch, Islamic Azad University, Ardestan, Iran \\ ${ }^{2}$ Hamedan Branch, Islamic Azad University, hamedan, Iran
}

\begin{abstract}
In this paper we describe a comparison between the methods of Variogram and Nettelton to establish the density of the Bouguer plane. The Nettelton's method is a common method for determining the density along a profile which is based on the least chosen profile's topographic resemblance with the chosen density of related to that profile of the region. The variogram method based on fractal geometry. This method is based on minimizing surface roughness of bouguer anomaly. The fractal dimension of surface has been used as surface roughness of bouguer anomaly. Using this method, the optimal density of Charak area in south of Hormozgan province can be determined which is $2 / 7 \mathrm{~g} / \mathrm{cm}^{3}$ forthe under-research area. The density of the Bouguer plane in the region by the Nettelton's method has been calculated $2 / 3 \mathrm{~g} / \mathrm{cm}^{3}$. This determined optimal density has been used in correcting and reviewing its result in the case of Isostazy state and some very good results have been achieved which has an amazing coincidence with the regional geology and the drilled exploration wells in the area.
\end{abstract}

Keywords: Fractal dimension- Topography- Bouguer anomaly -Optimal density -IsostasyHormozgan

Received: 15 November 2013/ Revised: 28 November 2013/ Accepted: 3 December 2013/ Published: 7 December 2013

\section{INTRODUCTION}

The word fractal is derived from the Latin word 'fructus' which means an irregularly broken and ground rock. It was brought up in 1975 for the first time by Benoit B. Mandelbrot (Mandelbrot,1975) In recent years, Mandelbrot's brownian fractional surfaces have attracted a lot of attention because of their noticeable similarity to topography (Fournier and fussell, 1982; 
Goodchild, 1982). Observing shapes in the nature, it is concluded that Euclideangeometry is not able to state and explain natural complex and apparently irregular shapes. In Euclidean geometry dimension is an integer such as one, two and three. As a consequence, Euclidean geometry is able to explain one, two, three and higher dimensional phenomena. The other observation is not to consider dimension of phenomena and events to be integer. In addition, we accept that dimension can be changed continuously from zero to one, one to two, two to three etc. For example, if a line is of dimension one and a plate is of dimension two, a dimension between one and two can be attributed to a hundreds-of-times broken line in accordance with intensity of breaks in the figure produced.

\section{FRACTAL METHOD (VARIOGRAM)}

Variogram method is widely used to identify dimension of fractal. Taking a large sample of couples of points (with different positions and distances) along with a profile and calculating the difference among their values, fractal dimension is easily obtained by drawing completely logarithmic graph of variance with respect to distance growth and calculating graph slope. Using this method, optimal density of the area can be achieved .

\section{GEOLOGY OF AREA}

The considered area lies between longitudes $53^{\circ}$ and $54^{\prime}$ to $54^{\circ}$ and $24^{\prime}$ east and latitude $26^{\circ}$ and $43^{\prime}$ to $26^{\circ}$ and $56^{\prime}$ north. This area is spread out to Lavaran from the east, to DehnoMaragh and Bahmani from the north, Kalat and Mazra'eJobran from the west and to Persian Gulf from the south. From a geological point of view and considering partitioning Iran, this under-research area is in Zagros area covering north parts of Bandar Abas to the west of Lengeport . Districts in this area belong to the end of mountains in south west of Zagros which is made up of two subareas of high Zagros and jagged Zagros. The main difference between these two sub-areas in the related part of Hormozgan province is mostly of structural differences, but taking sequences of stones into account, they do not differ.

\subsection{Implementation Theory of the Method in the Area}

Calculations on the data of complete bouguer anomaly of the studied area made by surface Variogram method are as follows. Firstly, a point in the area with identified longitude and latitude is considered as center and a circle, centered at this point with the largest possible radius to draw, is drawn to include data as much as possible. This maximum distance is divided to 30 equal groups. Then, variance of bouguer data difference for each group is calculated and its logarithm is drawn with respect to logarithm of each group differences (Aronson and Mark, 1984). After investigating the graph, points which are supported by Earth's rigid crust and show fractal feature are selected and then we fit the regression line of least squares with them. The slope of this straight line which satisfies the formula $\mathrm{y}=\mathrm{mx}+\mathrm{b}$ demonstrates fractal dimension of line, )

$$
\mathrm{E}\left\{\left(\mathrm{Z}_{\mathrm{P}}-\mathrm{Z}_{\mathrm{q}}\right)^{2}\right\}=\mathrm{K}\left(\mathrm{d}_{\mathrm{pq}}\right)^{2 \mathrm{H}}
$$


where $Z_{\mathrm{p}}$ and $Z_{\mathrm{q}}$ are surface values in the points q and $\mathrm{p}, d$ horizontal difference among the points and $\mathrm{H}$ is equal to (3-D). Drawing logarithm of variance of differences caused by local complications of the surface with respect to logarithm of distance among the points results in a graph which the existence of a linear relation along the domain implies self-similarity along that domain ,and its fractal dimension is gained by slope $\mathrm{b}$ of a drawn line in domain point. $\mathrm{D}=3-\mathrm{b} / 2$

Figure- 1. Contour map of complete bouguer anomaly with density $(2.3) \mathrm{g} / \mathrm{cm} 3$ and level line differences of 1 ( $\mathrm{m}$ gal)

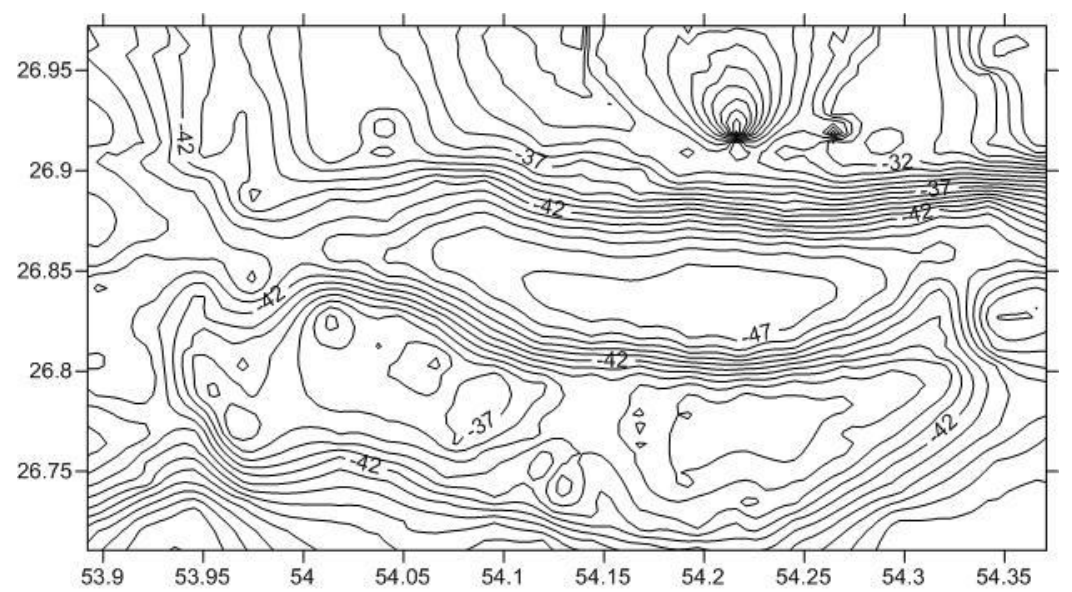

Figure- 2. Complete regression line of bouguer anomaly of the area with fractal dimension (2.42)

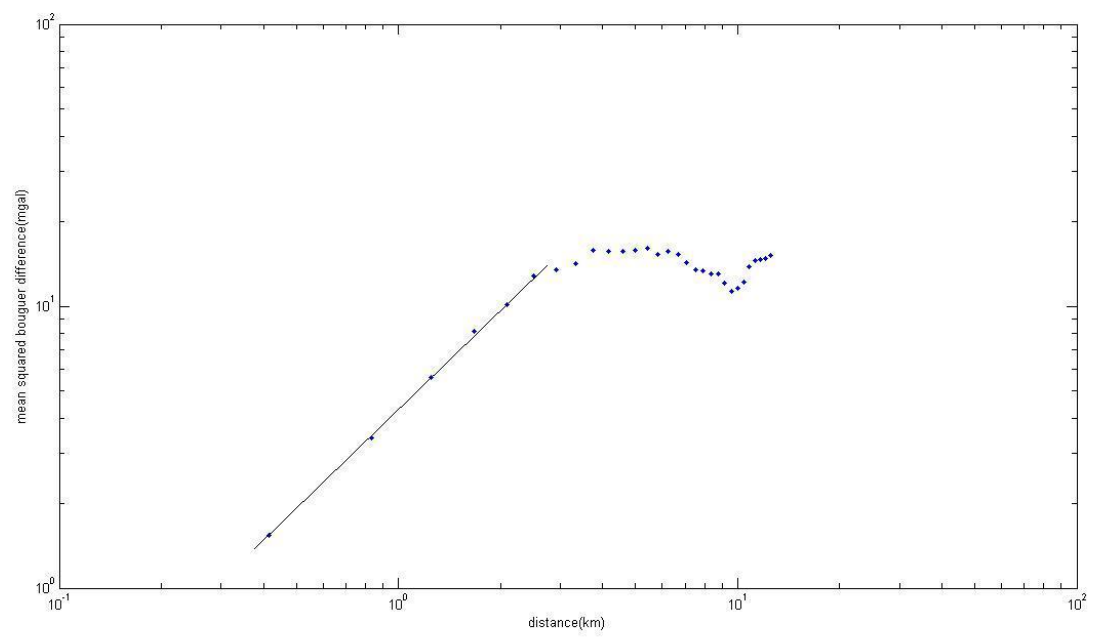

\subsection{Identification Scheme of Optimal Density in the Area}

In this section, to reduce the dimension of surface roughness of bouguer anomaly, optimal density is determined, and to achieve this goal, firstly, complete data of bouguer anomaly of the area with different density should be calculated. Then, fractal dimension of each new obtained data series is calculated using mentioned method and draw the results with respect to their 
density (Thorarinsson and Magnusson, 1988). In the obtained graph, the minimum shown dimension has the best density which is $(2 / 7 \mathrm{~g} / \mathrm{cm} 3)$ for the under-research area.

Figure- 3. Complete regression line of bouguer anomaly of the area with optimal density $\left(2 / 7 \mathrm{~g} / \mathrm{cm}^{3}\right)$ with fractal dimension $(2.24)$

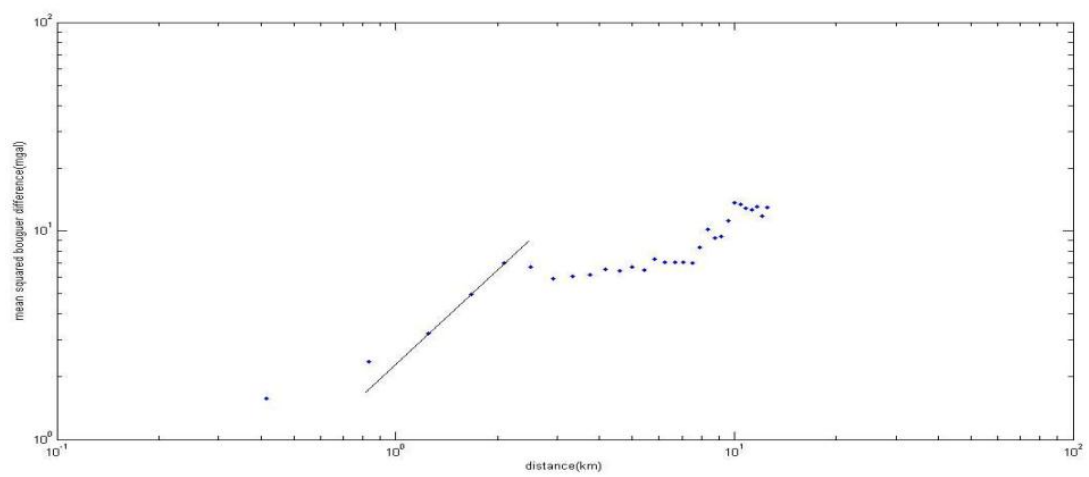

Figure- 4. Illustrating determination of optimal density of the area

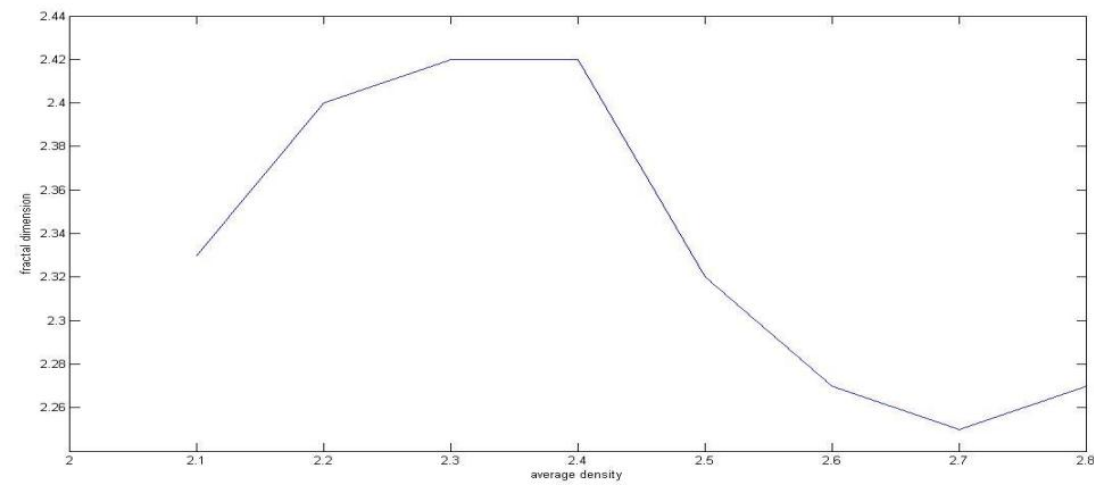

Figure- 5.contour map. The complete Bouguer anomaly of the region with the density $\left(2.7 \mathrm{~g} / \mathrm{cm}^{3}\right)$ and the balance distance $1 \mathrm{~m} \mathrm{Gal}$; by using the Variogram's method

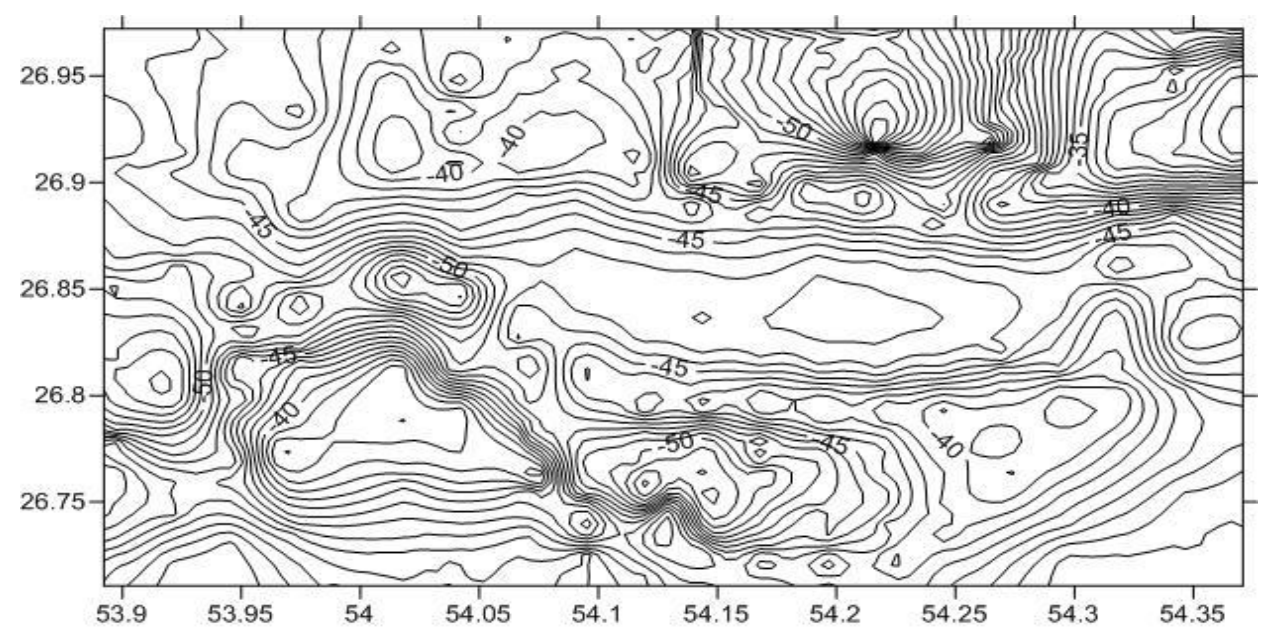


Review and comparison of the Bouguer anomalies by the Variogram's and Nettelton's methods with the topography of the area respectively. In this section we concentrate on analysing and comparing the Buguer anomaly with density $2.3 \mathrm{~g} / \mathrm{cm}^{3}$ and the Buge anomaly due to the optimum density of the area $2.7 \mathrm{~g} / \mathrm{cm} 3$ with the topography of area. For doing it we utilize from a profile that is caused in the topography of area. Profiles which is created in the map of the Bouguer anomaly of area has a better independence rather than the created Bouguer anomaly from the Nettelton's method compare with the topography of the area (Samadi,2013).

Figure- 6.graphic profile in the topography of the area A

A

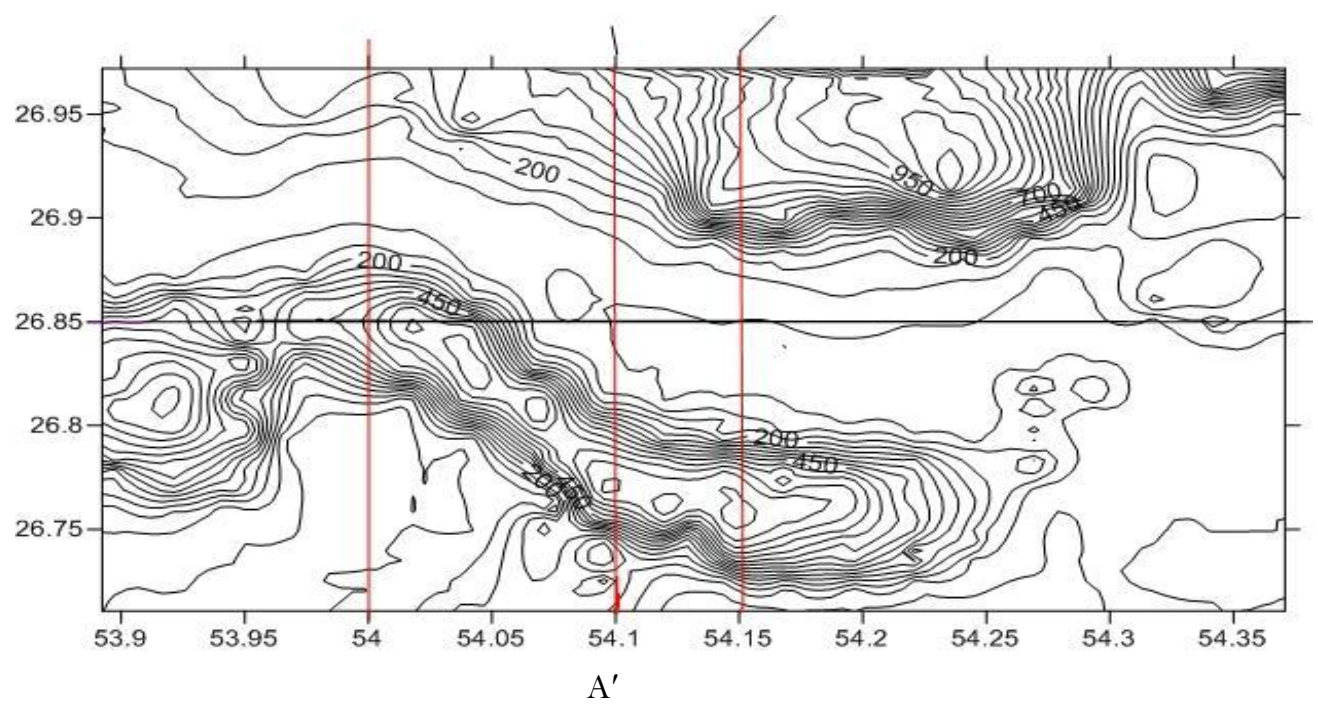

Figure- 7. Pic 7 graphic profile of the regional Buguer anomaly map in the Nettelton's method

A

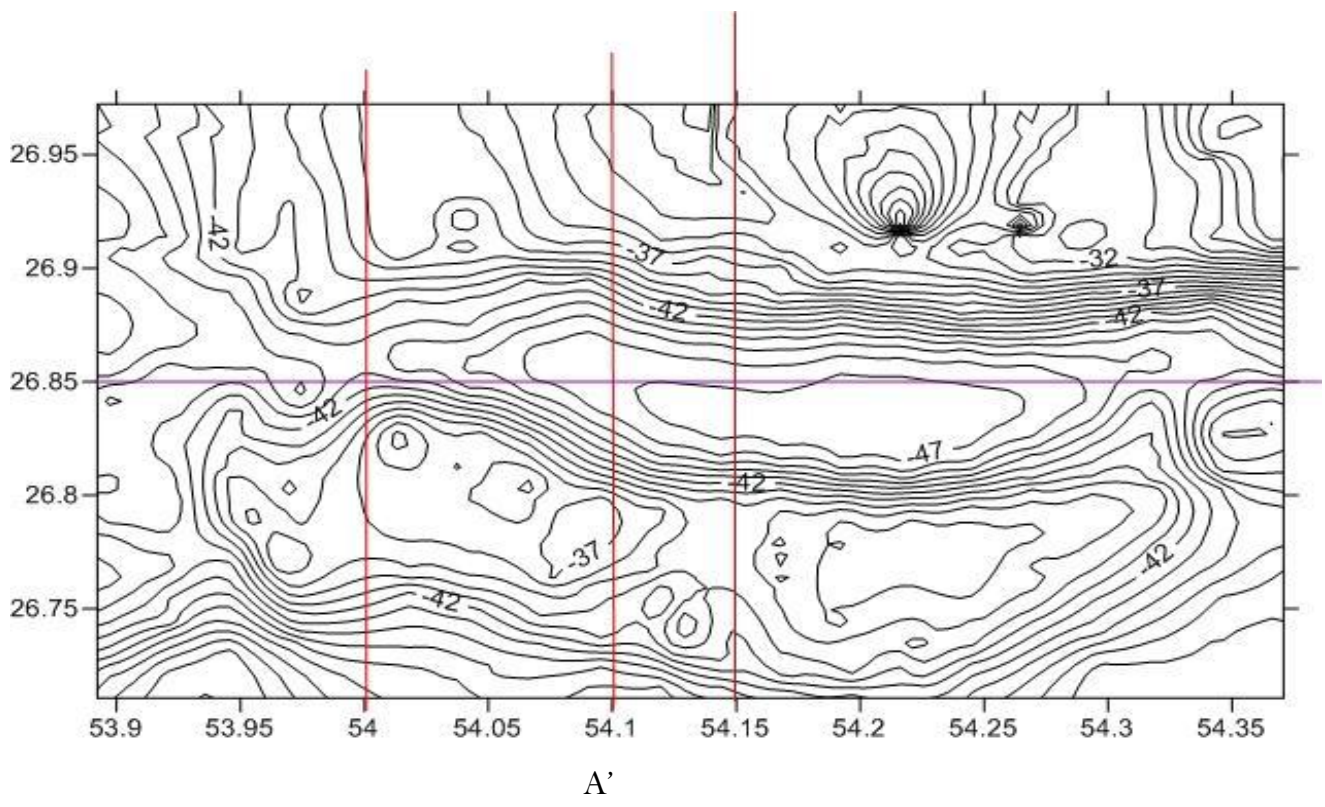


Figure- 8. graphic profile of the regional optimal BOUGUER anomaly map

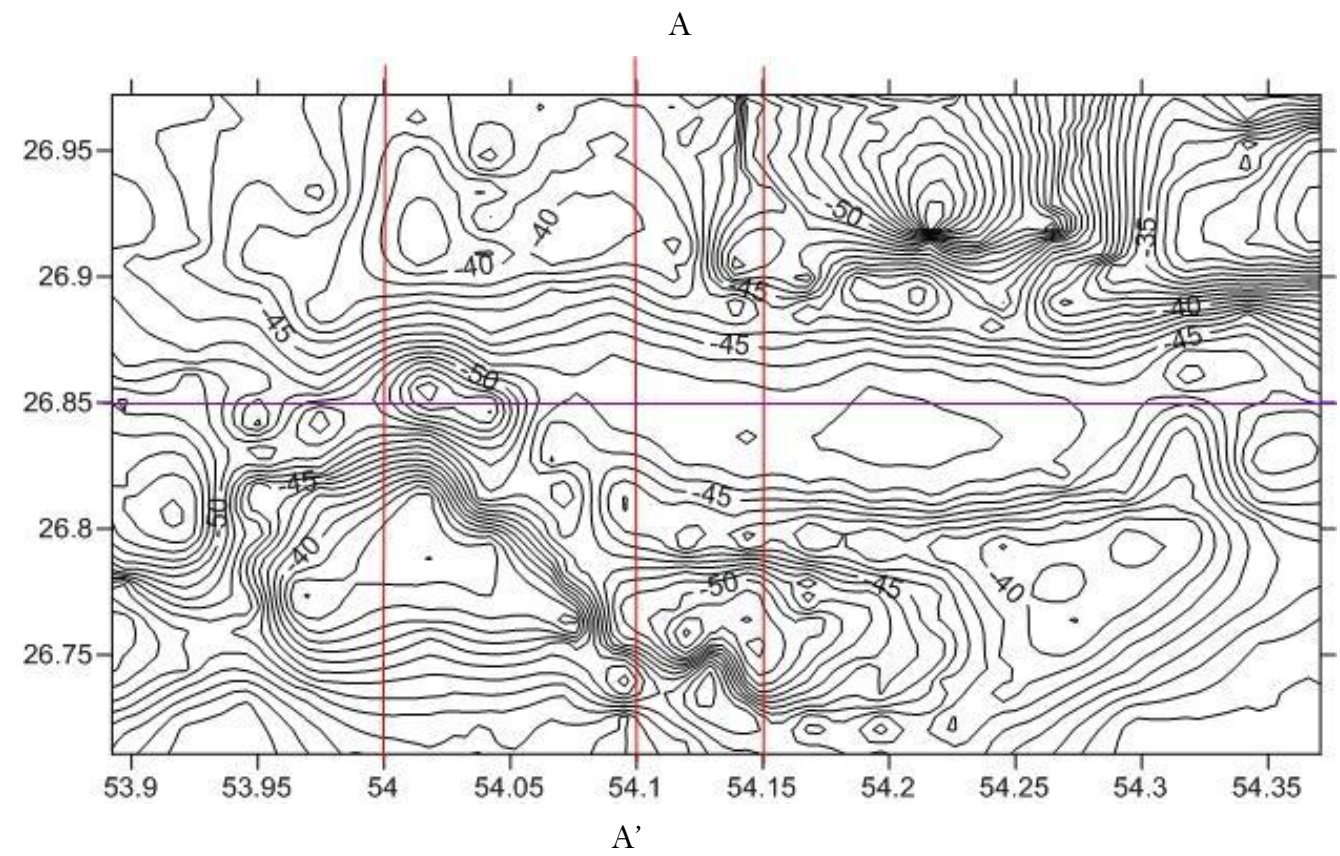

Figure-9. Two-dimensional topographic profile

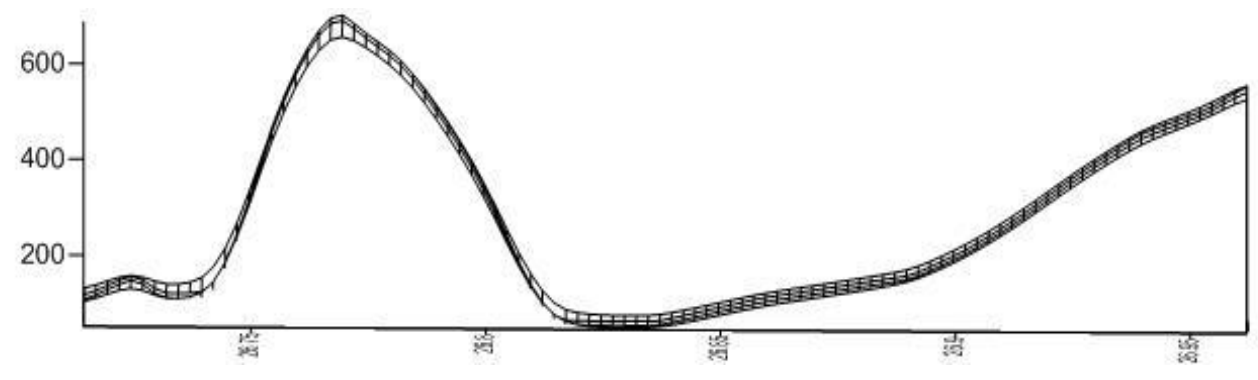

Figure-10. BOUGUER anomaly the method of two-dimensional profile of Nettelton

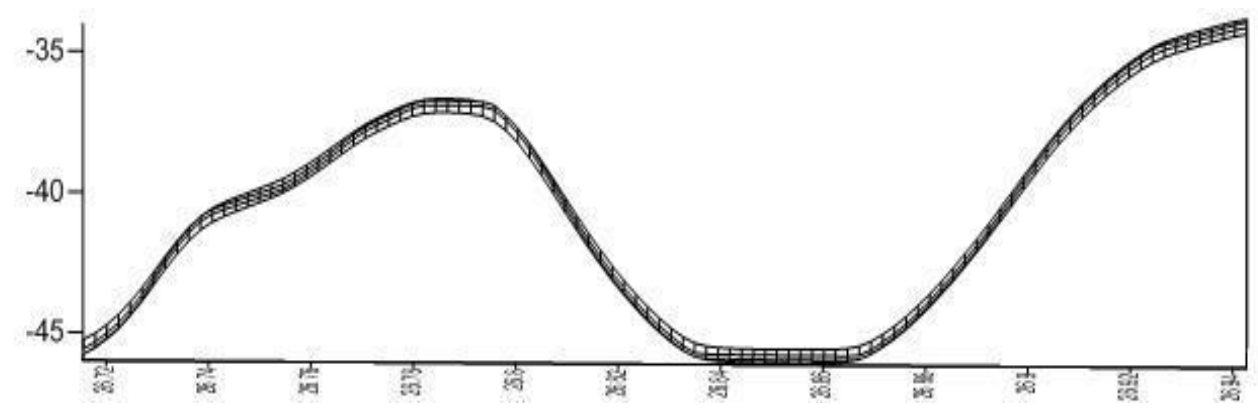


Figure- 11. Optimal BOUGUER anomaly the method of two-dimensional profile of Variogram

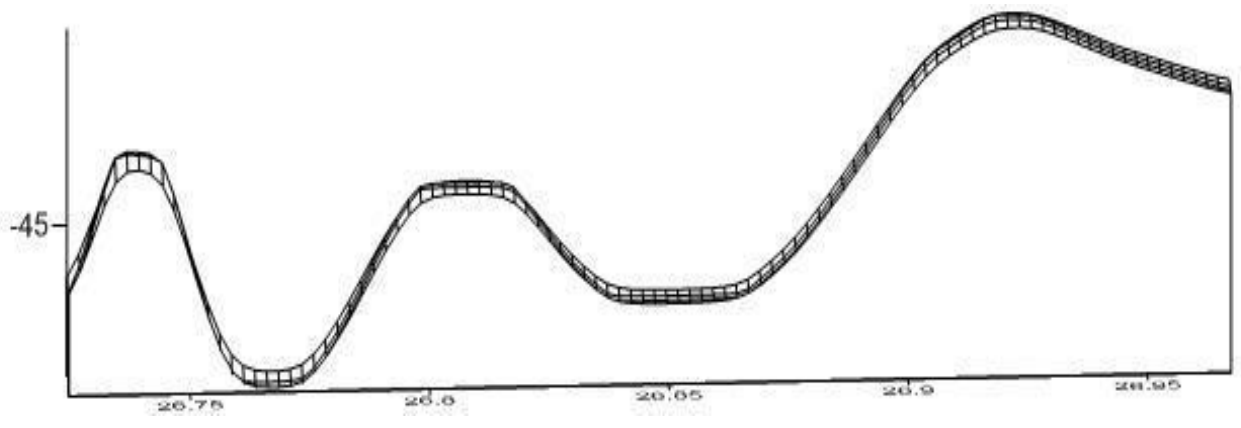

\section{COMPARISON OF OPTIMUM DENSITIES OBTAINED FROM THE NETTELTON'SMETHOD}

In this section we focus on comparative study between the complete Buge anomaly data that is obtained from optimal density of the region by the Variogram's method $\left(2 / 7 \mathrm{~g} / \mathrm{cm}^{3}\right)$ and the same that is acquired by Nettelton's method with density $\left(2 / 3 \mathrm{~g} / \mathrm{cm}^{3}\right)$ : which differenceduetothe changein thedensity ofthe dataisshownin following fig.

Figure- 12.Contourmapthe difference betweenoptimaldensity(variogram'smethod) andmajor density of the picked area (Nettelton'smethod) Thedistance between the balancelineis $1 \mathrm{mmGal}$

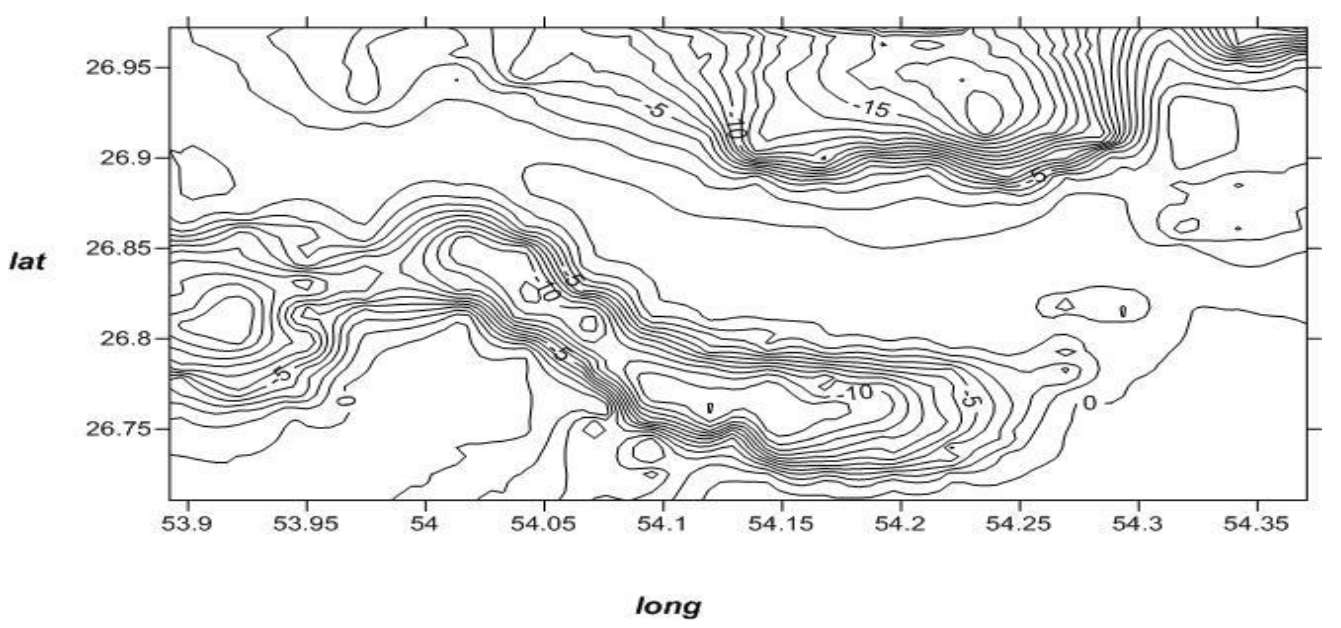

\section{CONCLUSION}

Usage of small and large amount of bouguer density in the bouguer plate and topography correction makes extra effect of topography on the results of bouguer anomaly. Supposing that gravitational field has usually less roughness in comparison with topography, we determine bouguer density with minimizing surface roughness of bouguer anomaly. The amount of this roughness has been determined by dimension of surface fractal.

- In the west of the area (about 53.92, 26.81) the anomaly caused by salty dome in contour map with density of 2.7 is determines more clearly and more definite 
- In the north of the area $(54.10,26.95)$ the salty dome in contour with density of 2.7 with respect to contour map with density of 2.3 is more clearly distinguishable

- Windows in Mishan formation (about 54.03, 26.86) which because of erosion caused displacement of Asmari limestone and is distinguishable in the contour map of topography of the area, in the contour map of bouguer anomaly with density of 2.7 is well-represented more clearly - In the center inclined to the west $(54.03,26.86)$ in the contour map with density of 2.7 a special anomaly can be seen that is likely caused by Barund's fault performance of north east- south west which made formations break and move and made waterway in the valley that cannot be seen in the contour map with density of 2.3 .

Funding: This study received no specific financial support.

Competing Interests: The authors declare that they have no competing interests.

Contributors/Acknowledgement: All authors contributed equally to the conception and design of the study.

\section{REFERENCES}

Aronson, P.B. and D.M. Mark, 1984. Scale-dependent fractal, dimensions of topographic surfaces. Math. Geol, 16(4): 671-683.

Fournier, A. and D. Fussell, 1982. Computer bendering of stochastic models,comm. Acm, 25(6): 371-384.

Goodchild, M.F., 1982. The fractional brownian process as a terrain simulationmodel proccedings. Thirteenth Annual Pittsburg Conference on Modeling and Bimulation, 13(5): 1133-1137.

Mandelbrot,B.B., 1957. How long is the coast of biritain?statistical self similarity and fractional dimention: Science, 156(3): 636-638

Samadi,H.R, 2013. Optimal density determination of bouguer anomaly using fractal analysis (case of study: Charak area, Iran). International Journal of Geography and Geology, 2(7): 80-85.

Thorarinsson, F. and S.G. Magnusson, 1988. Directional specteral analysis and filteringof geophysical maps. Geophysics, 53(2): 1587-1591. 